\title{
Akıl Yürütme Biçimleri Açısından Türk Sosyolojisinin Şekillenişi
}

\section{Shaping of Turkish Sociology in Terms of Forms of Reasoning}

\section{Gökhan V. KÖKTÜRK*}

Özet: Türk sosyoloji tarihinin resminin tamamlanmasında sosyologların akıl yürütme biçimlerinin ve bunda etkili olan sosyo-politik etkenlerin belirlenmesi çok boyutlu düşünebilmenin bir gereği olarak karşımıza çıkmaktadır. Bu bağlamda farkındalık ve strateji kavramları Türk sosyolojisi açısından daha da önem kazanmaktır. Türk sosyolojisinin şekilleniş̧inde farkındalık, strateji, Ziya Gökalp ve Durkheim belirleyici konumdadir.

Anahtar Sözcükler: Farkındalık, strateji, aklın işleyişi, Türk sosyolojisi

Abstract: In completing the picture of the history of the Turkish sociology, the socio-political factors affecting sociologists in their effective forms of reasoning must be put forward in a multi-dimensional manner. In this context, the concepts of awareness and strategy becomes more important. With the help of such awareness, the shaping of the Turkish sociology can be understood in a more complete manner especially through the works of Ziya Gokalp and Durkheim are decisive.

Keywords: Awareness, strategy, mind operation, Turkish sociology

Sosyologların ele aldığı, üzerinde çalıştığı ya da anlamlandırdığı konuları çok boyutlu ve tarihî bir bakış açısından düşünmesi; kendisi için altın değerinde olan sosyal değişme olgusunu gözden kaçırmaması gerektiğinin önemi ve aynı zamanda tek düzeliliğin ağına düşmemesi için önemli bir etken olduğu saptamasını yapmak, özellikle Türk sosyoloji tarihi çalışmaları açısından son derece önemlidir. Nitekim Osmanlı İmparatorluğu'nun yıkılışı Türkiye Cumhuriyeti'nin kuruluşu aşamasında yüzünü Batı'ya dönmek zorunda kalan Türk düşünce hayatının öncü aktörleri, sonradan derin bir sessizliğe bürünecek olan sosyolojiyi toplumu şekillendirmek ve istenilen yönü vermek için işlevsel görmüşler, sosyoloji de yapılan siyasi tercihleri olabildiğince desteklemiştir. $\mathrm{Bu}$ bağlamda kuruluşundan günümüze kadar sosyologların aklını nasıl işlettiğinin bilinmesi, bu süreçte etkisi altında kaldıkları sosyo-politik etkenlerin öne çıkarılması, Türk sosyoloji tarihi resminin tamamlanması girişimlerinde etkin bir yere sahiptir. Türk sosyolojisinin kurulduğu dönemi çok boyutlu düşünmek için öncelikle Batı düşünce hayatını bilimsel gelişme ve metodolojik gelişme süreçleri açısından iyi analiz etmek gerekmektedir. Bu doğrultuda Özlem'in $(1998,56)$ belirttiği gibi; modern bilim ve daha özel olarak doğa bilimi kavramı, aslında Yeni Çağın bir ürünüdür. Bu bağlamda; Batı düşünce dünyası özellikle kilise baskısından kurtulup, aklın ve bilimin önderliğinde Orta Çağ karanlığından sıyrılırken, Batı dış1 toplumlara da örnek teşkil etme misyonu kazanmıştır.

17. yüzyıl modern bilimin kökenlerini anlamamız açısından önemli bir dönemdir. Bu dönem özellikle Batı dünyasında ortaya çıkan sosyal ve siyasal değişimler sonucunda, doğayı ve toplumu anlama ve onu kontrol etme amacına yönelik çabalarda geleneksel ve dinî düşüncenin ye-

\footnotetext{
* Yrd. Doç. Dr., Akdeniz Üniversitesi, Edebiyat Fakültesi, Sosyoloji Bölümü, Antalya, gkokturk@akdeniz.edu.tr
} 
rini alan yeni bir düşünce tarzının geliştirildiği bir dönemdir. Rönesans bu anlamda Yeni Çağ'a geçit veren bir süreç niteliğindedir. Bu geçiş süreci feodal yapıların temelden sarsıldığ 1 , ticaretin gelişip teknik buluşların hız kazandığı, kentleşmenin arttığı bir dönemdir. Dolayısıyla imparatorluğun yıkılışı ve ulus devlet inşa sürecinde kendine önemli görevler düşen Türk sosyolojisi için, Batı dünyasındaki değişim ve dönüşümler geriden takip etmenin avantaja dönüştürülebileceği noktaları oluşturmaktadır. Bu dönem aynı zamanda Aydınlanma Dönemi olarak nitelendirilir. Dört ana noktada Aydınlanma Döneminin diğer dönemlerden farkını belirleyebiliriz: Birincisi; doğa üstünün doğalla, dinin bilimle, tanrısal buyruğun doğa yasasıyla ve din adamlarının filozoflarla yer değiştirmesi söz konusudur. İkinci olarak; sosyal, siyasal ve hatta dinsel bütün sorunların çözümünde bir araç olarak deneyin rehberliğindeki aklın yüceltilmesi söz konusudur. Üçüncüsü; insan ve toplumun mükemmelleştirilebileceğine ve dolayısıyla insan soyunun gelişmesine duyulan inançtır ve son olarak; Fransız devriminde kanla talep edilen, özellikle yönetimin baskı ve kötülüklerinden uzak tutulma hakkı olmak üzere, insan haklarına ilişkin talepler söz konusudur. Bu ayırıcı özelliklerden en önemlisi birincisi olarak gözükmektedir. Batı'nın tarihinde bilimsel devrimin rolünü küçümsemek olanaksızdır (Bierstedt, 1990, 18-19).

$\mathrm{Bu}$ genel gelişme çizgisi içinde, sosyal bilimlerin ve sosyoloji biliminin ortaya çıkışı bu dönemdeki gelişmeler temelinde olmuştur. Bu dönemin en etkili olayı özellikle sosyoloji için şüphesiz Fransız Devrimidir. Fransız Devrimi bütün Avrupa'yı sarsmış olan bir olaydır. Dolayısıyla yöneticiler, siyasetçiler, aydınlar toplum denen nesnenin kavranması, anlaşılması, bir düzene kavuşturulması, bu düzen temelinde yönetilmesi ve yönlendirilmesi gibi ihtiyaçlarla karşılaşmışlardır. Sosyal bilimi ortaya çıkışındaki bu tarihsel motifi göz ardı ederek kavramak mümkün değildir. Sosyolojinin bir Fransız olan A. Comte tarafından tesis edilmiş olması bir rastlantı değildir. Yine Comte, bilindiği üzere pozitivizmin de kurucusudur (Özlem, 1988, 58). 19. yüzyıla kadar sadece bilim terimi kullanılmışken, 19. yüzyılda sosyal bilimlerin ortaya çıkmasından sonra, Yeni Çağ başlarından beri sadece bilim terimiyle adlandırılan bilimsel faaliyetler için doğa bilimi terimi kullanılmaya başlamıştır. Doğa biliminin bir diğer adı matematiksel doğa bilimidir. Deneysel bilim, pozitif bilim gibi adlarla da anılır (Özlem, 1998, 15). Pozitif bir tümelci söylemin ürünü olan sosyal bilimler, Newton fiziği modeline göre kurulmuştur. Nasıl ki doğayı ona egemen olan yasaları ortaya koyarak açıklayan, yani nomotetik çalışan bir doğa bilimi varsa, tarihi ve toplumu da onlara egemen olan yasaları ortaya koyarak, yine nomotetik çalışan bir sosyal bilim de vardır. Sosyal bilimlerin pozitivist ve tümelci bir epistemoloji içinde ve belli politik-ideolojik istek ve amaçlar doğrultusunda yönlendirilmiş bilgi faaliyetleri olarak bu şekilde kurumlaşmaları, 19. yüzyılın ortalarında gerçekleşmiştir. O dönemde sosyal bilim adı altında anılan beş temel bilim var: Tarih, iktisat, sosyoloji, siyaset bilimi ve antropoloji. Bunların hepsi, pozitivist ve tümelci bir söylem içerisinde, yasa ortaya koyucu, yani nomotetik bilimler olarak kabul ediliyorlardı (Özlem, 1998, 17-18). Sosyal bilimler, Yeni Çağın "bilmek, yapabilmektir" sloganı altında pozitivist/evrenselci bir epistemoloji içinde ve belli politik-ideolojik istek ve amaçlar doğrultusunda yönlendirilmiş bilgi faaliyeti olarak kurumlaşmışlardır.

$\mathrm{Bu}$ anlamda sosyoloji ve de Türk sosyolojisi açısından etkin bir yeri olan Fransız düşünce dünyasının tarihsel gelişim sürecini analiz etmek önemlidir. Dolayısıyla sosyolojinin isim babası sayılan Comte'un çalışmalarının düşünsel arka planında yer alan bazı ana öğeleri belirlemek mümkündür. Bunlardan biri; 18. yüzyıl felsefesinde, metafiziğe karşı duruştur. Comte'un çalışmalarının St. Simon'dan kaynaklanan, sosyolojiye adını veren ve yeni bilim olduğu düşünülen şeyin mantıksal çerçevesini çizen bir gelişme çizgisi olduğu belirtilebilir. Diğeri; Marx tarafindan izlenen ve St. Simon'un fikirlerindeki öğelerin devrimci toplumsal dönüşümle yeniden ilişkilendirildiği çizgidir (Giddens, 1990, 252-253). Sosyoloji ortaya çıkışında kendisini diğer bilimlerle ilişkileri kapsamında tanımlamıştı. Nitekim Swingewood'un $(1998,62)$ belirttiği gibi; Comte'un bizzat ifade ettiği amac1, bütün mevcut bilgilerin bir sentezini yapmaktı. 19. yüzyıl özellikle Batı Avrupa sanayi devrimiyle birlikte gelen yapısal değişmelerin ve dolayısıyla 
toplum sorunlarının açık seçik ortaya çıktığı bir dönemdir (Gökçe, 1999³, 10). Comte pozitivizmi sosyolojinin gelişim süreci içinde doğa bilimleri ile toplum bilimleri arasında hiçbir amaçsal, yöntemsel ayrım gözetmeyen, doğa biliminin nesnesine yaptığını insan ve topluma yapmayı öngörmektedir.

Bu konuda ilk olarak belirlenebilecek nokta, Sezer'in $(1993,15)$ belirttiği gibi; sosyolojinin yüzyıllardan beri insanlığın ele alıp üzerinde düşündüğü sorunları, kendisine konu almasıdır. Bu durumda sosyoloji yeniliğini ve farklılığını konularında değil de konuyu ele alış ve değerlendiriş biçimlerinde aramak zorunda kalmıştır ve bu zorunluluk sonucunda yöntem konusu sosyolojinin temel sorunlarından birini oluşturmuştur. Sosyoloji, önce diğer bilimler önünde kendi varsayım ve önerilerinin bilimselliğini savunabilmek için yöntem konusunu ortaya atmıştır ve yine sosyolojinin konusu olan toplum olayları hiçbir biçimde deneye izin vermediği için önerilerinin sağlamlığını ve geçerliliğini kullandığı yöntemlerin bilimselliği ile kanıtlamaya çalışmıştır. Yöntem tutkusu, Descartes'çı düşüncenin başlıca özelliklerindendir. Descartes'da yöntem her bilimsel ya da felsefi çalışmada her kapıyı açabilecek bir anahtar olmaktan çok bir gerekliliktir. Her yöntem belli bir soruna göre düzenlenmiş bir usuller toplamı olduğundan o sorunun koşullarıyla belirlenmek durumundadır (Timuçin, 2000, 19-27). Görüldüğü gibi bilimsel bir disiplin olarak sosyoloji, köklerini 18. yüzyıl düşüncesinden alan modern bilimsel düşüncenin epistemolojik ve metodolojik kabullerine dayanan bir gelişme çizgisi içinde modernizmin bir ürünü olarak bilimler arasındaki yerini almıştır.

Sosyolojinin hedefi, doğa bilimsel yasaların nesnel konumunun aynına sahip olan ilkeleri formüle etmektir. Bilimsel yöntemin Bacon'cı bir biçimi, Durkheim'da belki de Comte'da olduğundan daha belirgindir. Sosyoloji de dahil olmak üzere her bilim, Durkheim'a göre, toplumsal olgularda gözlenen düzenlilikler üzerine kurulu serinkanlı tümevarımsal genellemelerden geçerek yavaş yavaş ve dikkatlice ilerler. $\mathrm{Bu}$, aslında, Comte'un pozitivist bir tarih anlayışını kurduğu yolundaki iddiası karşısında Durkheim'ın eleştirelliğinin gerçek nedenidir. Sosyolojinin bir toplumsal doğa bilim niteliğini almakla birlikte, doğalcılığı (natüralizm) yeğleyerek pozitivist etiketini reddederken Durkheim, kendi genel konumunu Comte'dan ayırmanın arayış1 içindedir (Giddens, 1990, 257). Nitekim Durkheim (1964) "The Rules of Sociological Method" adlı kitabının ön sözünde; günümüze kadar sosyologların çalıştıkları sosyal gerçekliklerde metodu tanımlama ve açıklamaya az yer verdikleri saptamasında bulunmaktadır. Bununla beraber Durkheim, sosyoloji ve onun metodunun tamamen felsefeden bağımsız olduğu iddiasını taşımaktadır. Çünkü sosyoloji, büyük felsefi doktrinlerin içinden doğmuştur, bazı felsefi sistemlere dayanan alışkanlığa sahiptir ve bu sosyolojiye ağır bir yük getirmektedir. Sosyoloji birbirini izler bir şekilde pozitivistik, evrimsel, idealistik felsefelerin etkisindedir, ki bu durum içeriği sadece sosyoloji olana kadar devam etmiştir.

1900'lü yıllara gelindiğinde ise Türk sosyo-kültürel yapısına egemen olan üç farklı düşünce sisteminin varlığı göze çarpmaktadır: Bunlardan Türkçüler ve İslamcılar, Batı'dan yalnız bilimsel metod ve teknolojilerin alınmasını savunmuşlar, buna karşılık Batıcılar Batı'nın kültürüyle birlikte bütün olarak alınmasını savunmuşlardır. Bilindiği üzere birbirlerinden bazı temel noktalarda ayrılsalar bile, egemen düşünce sistemlerinin tümü Batılılaşma hedefini taşımaktadır. Tüm bu gelişmelere bağlı olarak Sezer'in $(1989,7)$ belirttiği gibi; genel batıcılaşma akımı içinde, batı düşünce öge ve dalları Türkiye'ye ithal edilmeye başlanmış bu arada sosyoloji de yurdumuza girmiştir. Böylece teknik alanda başlayan batı bilim ve düşüncesinin Türkiye'de kökleşmesi toplum bilimleriyle de bütünleşmiştir. Bununla birlikte farklı sosyo-kültürel, ekonomik yapılara ve farklı sorunlara sahip olmalarına rağmen, Türkiye'de ve Avrupa'da sosyolojinin bir bilim dalı olarak kabul edilmesi aynı zamana, 19. yüzyıla rastlar. Fransa'dan sonra dünyada ikinci bağımsız sosyoloji kürsüsünün Türkiye'de kurulmuş olması çok önemli bir toplumsal olaydır. Türkiye'de ilk kez İstanbul Üniversitesi Edebiyat Fakültesinde 1916 yılında Ziya Gökalp tarafından İçtimaiyat Darülmasaisi adıyla sosyoloji resmen kurulmuştur. Ancak ilk sosyoloji 
dersleri 1913-1914'te verilmeye başlamıştır; 1924'te ise bütün liselerde ve öğretmen okullarında programa alınmıştır (Kasapoğlu, 1991, 31).

Türk sosyolojisine rengini veren ve temellerinin Batı'ya yönelik tercihlerle atıldığg sosyolojiyle tanışma adını verebileceğimiz Türk sosyoloji tarihinin ilk döneminde Durkheim'ın çok fazla etkisinde kalan, bunun yanında özgün görüşlerini de ortaya koyan Ziya Gökalp, Türk sosyolojisinin şekil almasında önemli bir isim olarak karşımıza çıkmaktadır. Türk sosyoloji tarihinin ilk dönemi itibarıyla ikinci isim olarak sürekli dile getirilen Prens Sabahaddin'in görüşlerinin deyim yerindeyse itibar görmemesi ve yeterli siyasi taraftar bulamaması sosyolojik gelişim sürecinde sosyo-politik değişkenlerin etki düzeyini anlamamızda etkili bir örnek teşkil etmektedir. Sosyolojiyle tanışma döneminde, özellikle kıta Avrupası'nda oldukça kökleşmiş ve sorgulanamaz niteliğe bürünmüş olan pozitivist düşünce, doğa ve diğer toplumlar üzerinde manipülasyon gücünü üst seviyeye çıarmış olmanın verdiği güvenle toplum içinde yaşanan sorunlara makro düzeyde çözüm arama yoluna gitmiş ve topluma istenilen şeklin verilebileceğine inanmış, sosyolojiyi de bu anlamda işlevsel görmüştür. Yeni kurulan bir ülke olan Türkiye Cumhuriyeti, temeli Türklük olan toplum inşasına yönelmiş bunun için de son derece etkisinde kalmış olduğu pozitivist düşüncenin topluma istenilen yönü ve şekli vermede önemli bir araç olarak gördüğü sosyolojinin makro düzeydeki analizlerini ve akıl yürütme biçimini, toplum inşasında etkin bir şekilde kullanmıştır. Aklın işleyiş yolları olarak tümdengelim ve tümevarım şeklinde yapılan yöntemsel bir belirlemenin ardı sıra Farkındalık ve Strateji olguları daha da önem kazanmaktadır. Farkındalık yöntemsel olarak ne aradığının ve aranılan bilgiye hangi yollardan ulaşılabileceğinin bilinmesi durumuna karşılık gelmekte, strateji ise farkındalık düzeyine sahip olunduğu anlamına gelmektedir. Başka bir deyişle, farkındalık olmadan, sorgulamadan aklını işlettiğini zannetmenin karşılığ yöntem, farkındalığa sahip olarak aklı işletme ise strateji olarak karşımıza çıkmaktadır. Türk sosyoloji tarihi açısından ilk dönem itibarıyla yöntemsel açıdan farkındalığın üst düzeyde olduğunu, dolayısıyla aklın işleyiş yolunun stratejik olarak belirlendiği saptamasını yapmak mümkün gözükmektedir. Çünkü Türk sosyolojisi ilk yılları itibarıyla özellikle Kıta Avrupası'nda hızla yükselen ampirik uygulamalara yönelmemiş, bilimsel faaliyeti kuramsal düzeyde ele almıştır.

Aklını tümevarım yoluyla işleten Türk sosyolojisi yüzünü döndüğü Batı düşünce dünyasında ulaşılmış olan genel bilgilerden, özellikle uluslaşma sürecini büyük oranda tamamlamış olan Fransa'dan devşirdiği bilgilerle, özelin bilgisine bir başka deyişle yeni kurulan bir ülkenin Osmanlıdan kalan toplumunu uluslaştırma çabalarına girişmiştir. Bu aşamada Türk sosyolojisi yeni bilgiler veya kuramlar ortaya koymaktansa, bu bilgileri daha önceden oluşturulmuş genel bilgiler içinde arama yoluna gitmiştir. Türk sosyolojisi açısından akıl yürütme biçimlerinden biri olan tümevarım yoluyla özelin bilgisine ulaşmaya çalışmak, tümevarımın kesin sonuçlar verme olasılığından yararlanarak ulus devlet inşasında üzerine düşeni tam olarak yerine getirme kaygısından kaynaklanmaktadır. Bu noktada tümevarımın dayandığı temel görüşlerden biri olan bütünün bilgisinin parçalar tarafından da taşınıyor olması, Türk sosyolojisi açısından özellikle Ziya Gökalp'ın Hars ve Medeniyet Ayrımı, Batı Medeniyeti Dairesine dahil olunması görüşlerinde sonraları ise Hilmi Ziya Ülken'in Milletlerarası Seviye görüşlerinde net bir şekilde gözlemlenmektedir.

Ziya Gökalp'ın ömrü boyunca sergilediği düşünsel değişimleri; toplumsal koşulların değişmesi ya da kendisinin kararsızlığı olarak değil Batı düşünce dünyasındaki köklü değiş̧imler, bunalımlar ve dönüşümler açısından anlamaya çalışmak, Osmanlı İmparatorluğu'nun son dönemini ve Türkiye Cumhuriyeti'nin kuruluş dönemini anlamlandırmamız açısından son derece önemlidir. Bu bağlamda konuya kişisel refleks ve tutarsızlık olarak yaklaşmak, Türk düşünce hayatındaki altyapı eksikliğini ve önemli bir boyutu oluşturan entelektüel tembelliği göz ardı etmemize yol açmaktadır. Cumhuriyetin ilk yıllarında milli devletin inşa sürecinde acelecilik ana karakter özelliğini taşıyan bürokratik zihniyet, Türk sosyolojisini toplumu ait olmadığı bir 
medeniyet dairesine katma telaşına itmiştir. Kökleri Descartes'a inen, Bacon ve Newton ile en üst seviyesine ulaşan yöntem tutkusu, doğaya, diğer toplumlara ve kendi toplumlarına egemen olmak isteyen Batı dünyasını doğa bilimlerine yöneltmiş, kendine Batıyı sorgulamadan takip ve yer yer de taklit etmeyi görev edinen Türk sosyolojisi için yeni kurulan toplumun inşasında yol gösterici olmuştur.

Sosyolojinin hedefi, doğa bilimsel yasaların nesnel konumunun aynına sahip olan ilkeleri formüle etmektir. Bilimsel yöntemin Bacon'c1 bir biçimi, Durkheim'da belki de Comte'da olduğundan daha belirgindir. Sosyoloji de dahil olmak üzere her bilim, Durkheim'a göre, toplumsal olgularda gözlenen düzenlilikler üzerine kurulu serinkanlı tümevarımsal genellemelerden geçerek yavaş yavaş ve dikkatlice ilerler. $\mathrm{Bu}$, aslında, Comte'un pozitivist bir tarih anlayışını kurduğu yolundaki iddiası karşısında Durkheim'ın eleştirelliğinin gerçek nedenidir. Sosyolojinin bir toplumsal doğa bilim niteliğini almakla birlikte, doğalcılığı (natüralizm) yeğleyerek pozitivist etiketini reddederken Durkheim, kendi genel konumunu Comte'dan ayırmanın arayışı içindedir (Giddens, 1990, 257). Durkheim'ın sözü edilen bilimsel faaliyetlerle ilgili ayırıcı nitelikteki görüşleri, Türk sosyolojisinin kurucusu olan Ziya Gökalp'ta etkisini göstermiş, bilimsel araştırmanın amacının pratik değil teorik olduğu görüşü ile stratejik düşüncenin somut örneğini vermiştir.

\section{KAYNAKÇA}

Bierstedt, R. (1990), 18. yüzyılda Sosyolojik Düşünce. Ed. T. Bottomore, R. Nisbet. Sosyolojik Çözümlemenin Tarihi. Çev. Uygur Kocabaşoğlu. Ankara: V Yayınları.

Giddens, A. (1990). Pozitivizm ve Eleştiricileri. Ed. T. Bottomore, R. Nisbet. Sosyolojik Düşüncenin Tarihi, Çev. Levent Köker. Ankara: V Yayınları.

Gökçe, B. $\left(1999^{3}\right)$. Toplumsal Bilimlerde Araştırma. Ankara: Savaş Yayınevi.

Kasapoğlu, A. (1991). Türkiye'de Sosyolojinin Sorunları. Milli Kültür, Nisan, 83, 31-36.

Özlem, D. (1998). Doğa Bilimleri ve Sosyal Bilimler Ayrımının Dünü ve Bugünü. Toplum ve Bilim, 76, Bahar, 7-39.

Sezer, B. (1993). Sosyolojide Yöntem Tartı̧̧̧aları. İstanbul: Sümer Kitabevi.

Swingewood, A. (1998). Sosyolojik Düşüncenin Kısa Tarihi. (Çev. Osman Akınhay), Ankara: Bilim ve Sanat yayınları.

Timuçin, A. (2000). Descartes 'çı Bilgi Kuramının Temellendirilişisi. İstanbul: Bulut Yayınları. 